\title{
Induction machines diagnosis by the time's harmonics
}

\author{
Abderrrahim Allal $^{* 1}$, Abderrahmane Khechekhouche ${ }^{1}$, Zied Driss $^{2}$ \\ ${ }^{I}$ Technology faculty, University of El-Oued, ALGERIA \\ ${ }^{2}$ Laboratory of Electromechanical Systems (LASEM), ENIS, University of Sfax, TUNISIA \\ Email*: allalabderrahim@yahoo.fr
}

\begin{abstract}
The induction motor is currently becoming the key element of most industrial equipment. Despite these advantages, a certain number of constraints of very different natures can affect the lifetime of this machine, causing considerable economic losses. This work is the study experimental of defects for an asynchronous machine (with and without defect). After having described the main defects that can occur on these. In this study, we propose a method called induction machines diagnosis by the time's harmonics. This technique is based to study the influence of a defect of short-circuiting on the studied induction motor, we will find the rank of the harmonic of the most influenced by the number of the rank default. this study will find the diagnostic index of induction motor with stator default using the time harmonics. The results obtained show that the 3rd order time-harmonic is very sensitive compared to the other harmonics.
\end{abstract}

Keywords: induction motor, spectral analysis, stator fault, diagnosis, short circuit, time harmonics.

Received: 25/10/2020 - Accepted: 01/12/2020

\section{Introduction}

Induction motors are electric motors very much abandoned in the markets and they are widely used in all industrial applications; because of their simplicity, reliability, robustness and above all because of the possibility of adjusting the speed of rotation by the availability of power converters [1]. It is well known that the detection and diagnosis of failures in its engines make it possible to move from preventive maintenance to predictive maintenance of electrical machines during scheduled downtimes while avoiding unscheduled shutdowns [2]. For problem detection and fault diagnosis, it is very necessary to know whether a fault affects the system via online measurements and this has been done by a group of researchers [3]. According to specialists in the field of diagnostics, it is not only necessary to detect the defect, but it is also necessary to locate it and find its origin [4, 5]. Many methods of induction motor fault detection are published and offered by research in journals conducted by diagnostic laboratories. They proposed an in-line induction motor diagnostic system based on Motor Current Signature Analysis (MCSA) with various advanced signal processing algorithms. Over the past decades; there is much work in progress to find the best diagnostic technique [6, 7]. Another study proposes a more advanced signal processing method based on the ParkHilbert "Park-Hilbert" transformation (PVSMP-H). This research group used "fleet vector square modulus" (PVSM) and line current to obtain "motor square current signature analysis" (MSCSA) [8-11]. Another advanced technique called the "Hilbert Park vector product approach" (HPVPA) which is inspired. They used "Park's vector product approach (PVPA) for the diagnosis of induction motors" which is based on an improved combination of the Hilbert transform and Park's [12-17]. In this study, we propose a method called induction machines diagnosis by the time harmonics. This technique is based to study the influence of a defect of short-circuiting on the studied induction motor, we will find the rank of the harmonic of the most influenced by the number of the rank fault. But in the real case, it is 
very difficult to find a perfectly balanced power source, if not impossible, a well-centred winding as well as an ideally symmetrical geometry. An imbalance in the voltages will cause the creation of negative sequence (reverse field) currents in the stator windings which give rise to other harmonic frequencies in the stator windings. This gives us, finally, harmonics not only multiple of 3 but odd such as fs, $3 \mathrm{fs}, 5 \mathrm{fs}, 9 \mathrm{fs}, \ldots$ We obtain time harmonics whether for healthy or faulty operation.

\section{Method and experience}

\section{II.1. Materials used}

Two identical induction motors used, in the Electrical Engineering Laboratory of El Oued University, is threephase, $3 \mathrm{~kW}, 50 \mathrm{~Hz}, 2$ poles, squirrel-cage with 28 bars at the rotor and 360 turns in series per phase :

1) - healthy motor runs at full load (100\%)

2) - motor with stator faults runs at full load (100\%) with two cases

- short circuits between $5 \%$ of turns

Figure 1 shows two induction motors well prepared for the experimental tests the first is a healthy motor to give healthy spectral analysis the second is a motor with short circuit sockets to create artificial stator faults.

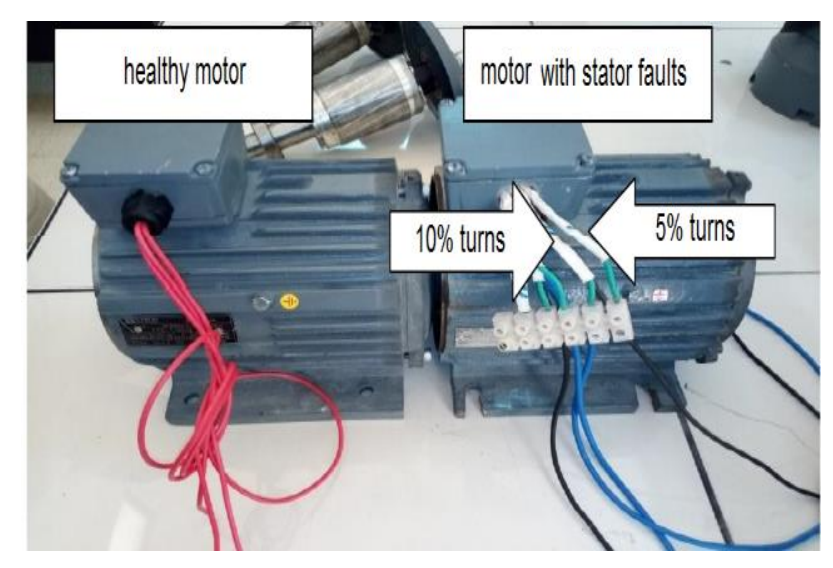

Figure 1. Three-phase induction motors ( $3 \mathrm{kw})$

Figure 2 shows the current sensor of a phase, with a calibre of 10 Amps to take the image of the current to be processed in the Pasco 750 interface.

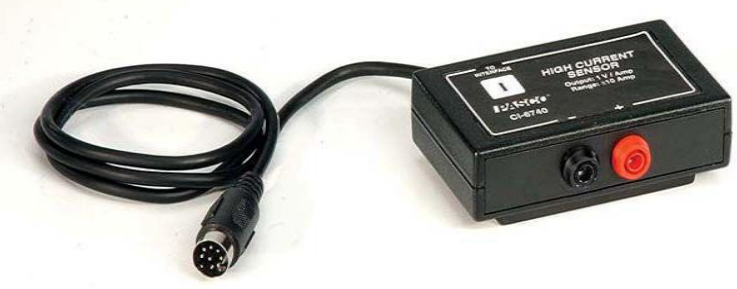

Figure 2. Current sensor

Figure 3 shows the Pasco 750 interface processes the image of the current extracted from the current sensor to visualize the spectrum through the software installed in the computer.

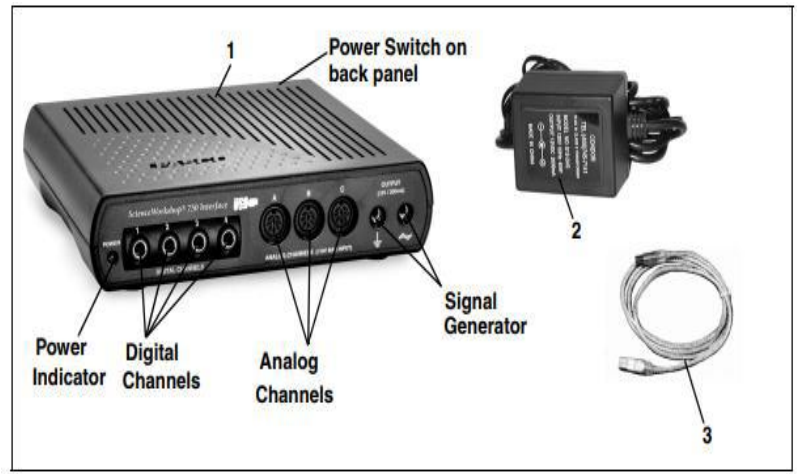

Figure 3. Interface Pasco 750 (1. Model No. CI-7599. 2.Transformer for power supply. 3- USB)

\section{II.2. Description of the signal extraction tool}

Figure 4 shows the experiment setup which gives the data acquisition of the motor current signal. The various faults which affect the IM will give rise to an influence on the signals coming from this IM by the modulation of their amplitudes at the characteristic frequencies of these faults. It is necessary to take care with a very satisfactory resolution to make appear the various additional lines the sidebands to be able to easily analyze and diagnose our ME.

As an example, we are going to do tests with our experimental bench which has an IM with stator fault at full load. For this, we will choose an acquisition time of $\mathrm{Ta} \approx 10$ seconds, which implies that the total number of samples $(\mathrm{Ne}=20000)$ : the number of samples by second of our results is therefore equal $\Delta \mathrm{Ne}=\mathrm{Ne} / \mathrm{Ta}=2000$ samples/second. 


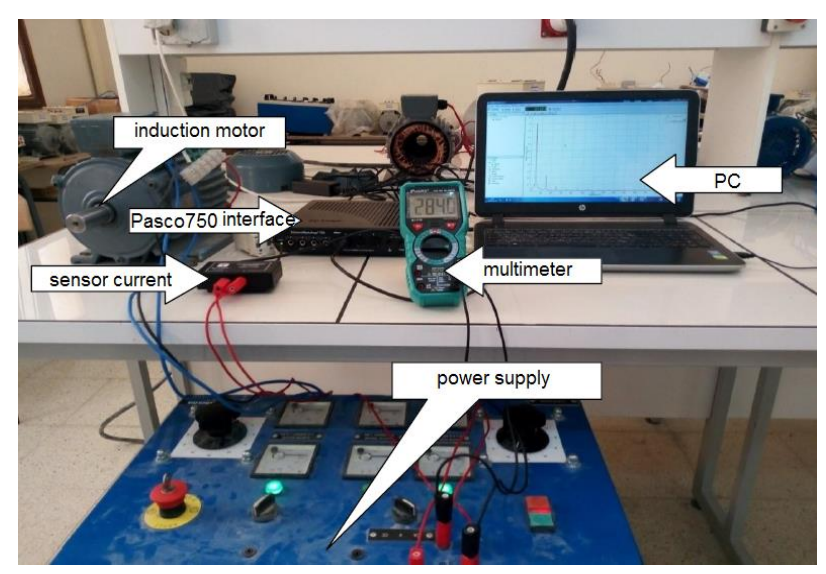

Figure 4. Experiment setup

\section{Results and Discussion}

\section{III.1. Case of a healthy machine}

Figure 5 shows the experimental spectrum of the stator current with its harmonics (healthy state). It is shown also how the evolution of time harmonics, their amplitudes and their specific frequencies which are multiples of 3 compared to the supply frequency with the healthy motor operating at no-load.

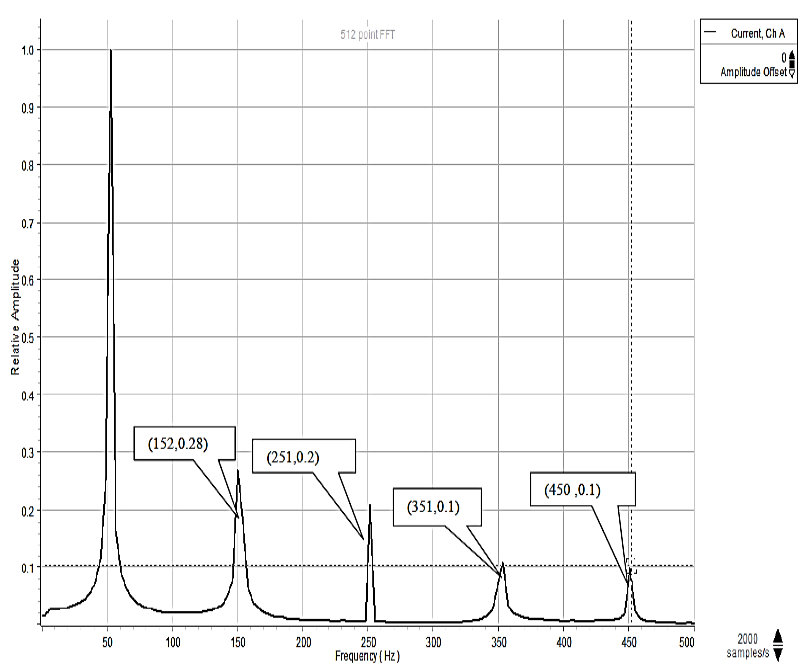

Figure 5. Experimental spectrum of the stator current with its harmonics (healthy state)

Figure 6 shows the evolution of the motor current in the time domain (2.7 Amperes) which is non-sinusoidal due to the imbalance of the motor and the non-symmetry of the materials of its manufacture.

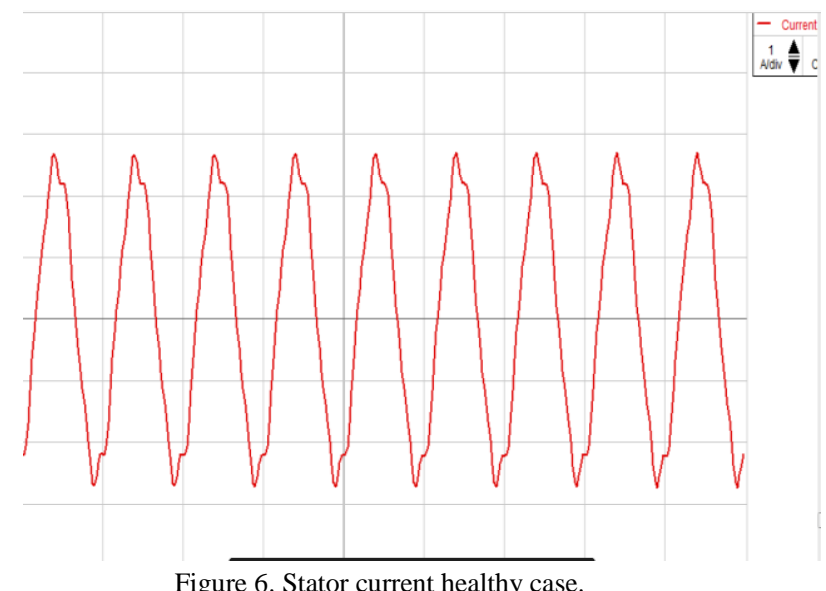

III.2. Case of a machine with stator short-circuit

Figure 7 shows the experimental FFT of the stator current with its time harmonics (with stator short-circuits $5 \%$ of turns). We notice the increase of time harmonics

in the case of stator fault with 5 percent of turns in phase A.

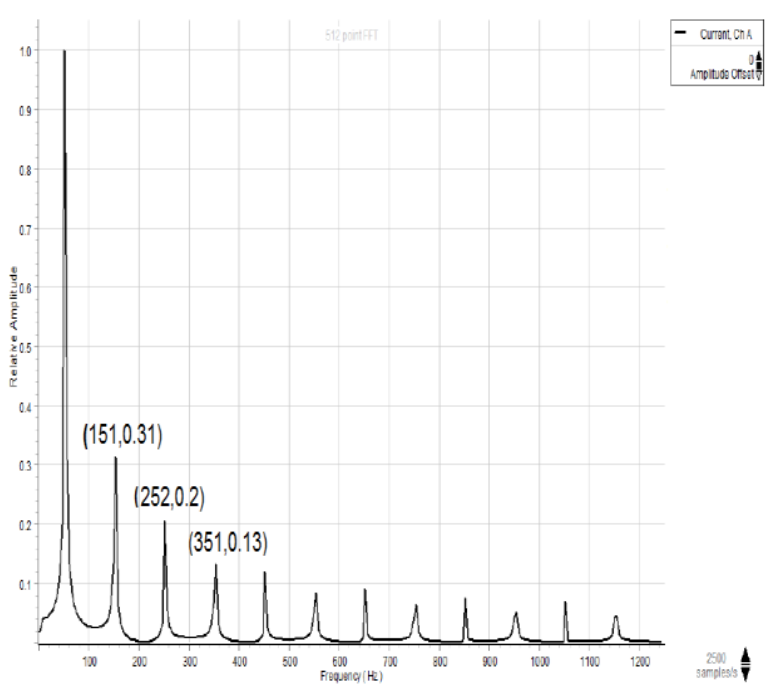

Figure 7. Experimental FFT of the stator current with its time harmonics (with stator short-circuits $5 \%$ of turns)

Figure 8 shows the evolution of the motor current in the time domain ( 3 Amperes) which further distorted the sinusoidal shape of the currents due to the stator fault. 


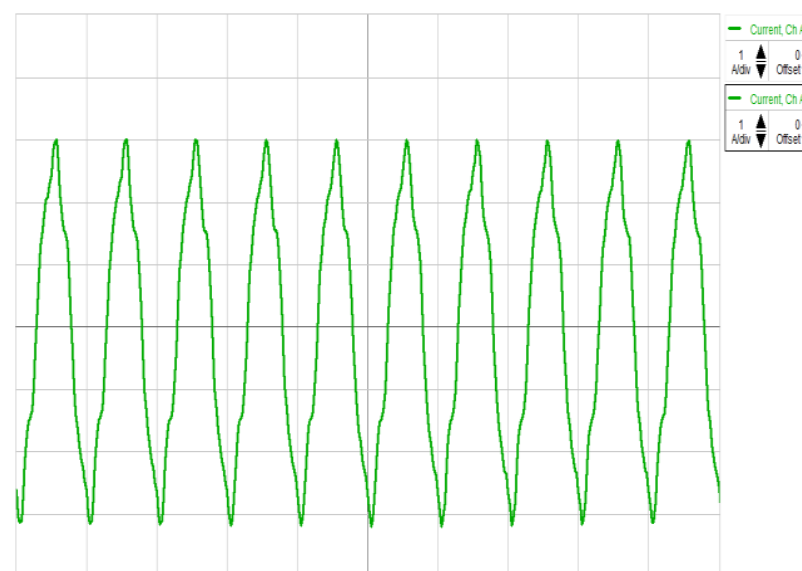

Figure 8. Stator current faulty case.

Figure 9 shows the experimental spectrum of stator current with its harmonics. The experimental spectral analysis of the stator current shows that the 3rd order time-harmonic is very sensitive compared to the other harmonics.

The time harmonics are given, generally, by the following formula:

$$
\mathrm{TH}_{\mathrm{n}}=\mathrm{\eta} * \mathrm{f}_{\mathrm{s}}
$$

Where

$\mathrm{n}$ : is the time-harmonic order.

$\mathrm{f}_{\mathrm{s}}$ : is a power frequency $(50 \mathrm{~Hz})$.

$\eta=1,3,5 \ldots$.

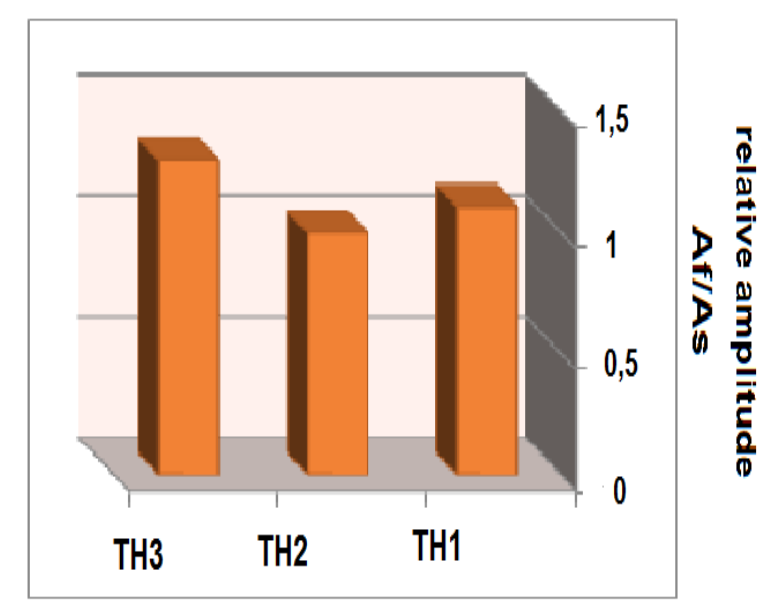

Figure 9. Experimental spectrum of stator current with its harmonics

\section{Conclusion}

This experimental study was carried out in the electric freezing laboratory of the University of El-Oued. This study is focused on the stator faults of the electric induction motor, such as what we have done (short circuit between the turns). The results obtained show that there is a remarkable increase in the amplitudes of the time harmonics but there is also a difference between these amplitudes as a function of their sensitivity. The experimental spectral analysis of the stator current shows that the time harmonics of order 3 are more sensitive than the other time harmonics of order 2 and order 1 influenced. For this, we can consider that the time harmonics of order 3 are the diagnostic index of asynchronous stator motors.

\section{References}

[1] M. Blodt, P. Granjon, B. Raison, G. Rostaing, "Models for bearing damage detection in induction motors using stator current monitoring", IEEE Trans. Ind. Electron, Vol. 55, (No. 4), 2008, p 1813- 1822.

[2] M. Boucherma, M. Y. Kaikaa, A. Khezzar, Park model of squirrel cage induction machine including space harmonics effect, Journal of Electrical Engineering, Vol 57 (No.4), 2006, p 193-199.

[3] E. Lughofer, E. P. Klement, "Model-based fault detection in multi-sensor measurement systems, Technical report Full/Tr/0303”, Johannes Kepler University Linz, Austria.

[4] S. Ben Salem, K. Bacha, A. Chaari, "Support vector machine-based decision for induction motor fault diagnosis using air-gap torque frequency response", International Journal of Computer Applications, Vol 38, No.5, 2012, pp. 27-33.

[5] S. Ben Salem, K. Bacha, A. Chaari, "Support vector machine-based decision for mechanical fault condition monitoring in induction motor using an advanced HilbertPark transform”, ISA Trans., Vol 51, No.5, 2012, pp. 566572.

[6] T. Sribovornmongkol, "Evaluation of motor online diagnosis by FEM simulations", Thesis, Royal Institute of Technology Stockholm, Sweden, 2006.

[7] K. Bacha, S. Ben Salem, A. Chaari, "An improved combination of Hilbert and Park transforms for fault detection and identification in three-phase induction motors", Electrical Power and Energy Systems, Vol 43 No.1, 2012, pp.1006-1016.

[8] Mohamed Sahraoui, Adel Ghoggal, Salim Guedidi, Salah Eddine Zouzou, "Detection of inter-turn short-circuit in induction motors using Park-Hilbert method", International Journal of System Assurance Engineering and Management, Vol 5, No.3, 2014, pp. 337-351.

[9] M. Sahraoui, "Etude comparative des méthodes de diagnostic des machines asynchronies (Comparative study of the methods of diagnosis in the asynchronous machines)", Thesis for the degree of Doctor of Science, Biskra university, Algeria, 2010.

[10] V. F. Pires, M. Kadivonga, J. F. Martins, A.J. Pires, "Motor square current signature analysis for induction motor rotor diagnosis", Measurement, Vol 46, No.2, 
2013, pp. 942-948.

[11] A. Allal, B. Chetate, "High sensitivity detection of the stator short-circuit faults in induction motor using Hilbert Park's vector product”, J. Fundam. Appl. Sci., Vol 11, No 2, 2019, pp. 994-1022.

[12] M. Sahraoui, S. E. Zouzou, A. Ghoggal, S. Guedidi, "A new method to detect inter-turn short- circuit in induction motors, 19th ed., International Conference on Electrical Machine (ICEM,2010 -Rome, Italy), IEEE, 2010, pp. 1-6.

[13] S. E. Zouzou, M. Sahraoui, A. Ghoggal, S. Guedidi, "Detection of inter-turn short-circuit and broken rotor bars in induction motors using the partial relative indexes: application on the MCSA", 19nd ed., International Conference on Electrical Machine (ICEM,2010), Rome, Italy, IEEE, 2010, pp. 1-6.

[14] A. Allal, B. Chetate, D. Benattous, "The Instantaneous Power Approach for Rotor Cage Fault Diagnosis in Induction Motor", 6 th Symposium on Hydrocarbons and chemistry ISHC6, 2012, Zeralda, Algeria.

[15] I. Chouidira, K. Djalal Eddine, H. Benguesmia, "Detection and Diagnosis faults in Machine asynchronous based on single processing", International Journal of Energetica (IJECA), Vol 4, No. 1. 2019, pp. 11-16.

[16] A. Allal, B. Chetate, “ A new and best approach for early detection of rotor and stator faults in induction motors coupled to variable loads", Frontiers in Energy, Vol 10, No.2, 2016, pp. 176-191.

[17] A. Allal, "Nouvelles méthodes et techniques de diagnostic des machines asynchronous à rotor en cage d'écureuil (New methods and diagnostic techniques asynchronous machines of squirrel cage rotor", Thesis for the degree of Doctor of Science, Boumerdes University, Algeria, 2017. 